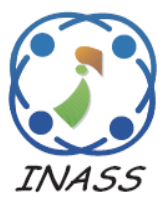

\title{
A Coplanar Waveguide Fed Asymmetric Ground Frequency Reconfigurable Antenna
}

\author{
Maddela Vijaya Lakshmi ${ }^{1,2 *} \quad$ Pardhasaradhi Pokkunuri $^{3} \quad$ Boddapati Taraka Phani Madhav $^{3}$ \\ ${ }^{1}$ Department of Electronics and Communication Engineering, \\ Koneru Lakshmaiah Education Foundation, AP, India \\ ${ }^{2}$ Department of Electronics and Communication Engineering, \\ St. Martin's Engineering College, Secunderabad, Telangana, India \\ ${ }^{3}$ Antennas and Liquid Crystals Research Center, Department of Electronics and Communication Engineering, \\ Koneru Lakshmaiah Education Foundation, AP, India \\ * Corresponding author's Email: btpmadhav@kluniversity.in
}

\begin{abstract}
A coplanar waveguide fed asymmetric ground frequency reconfigurable antenna is designed and analyzed in this paper. The proposed antenna is occupying the compact dimension of 50X45X1.6 mm on FR4 substrate with dielectric permittivity 4.4. The designed antenna is operating in the wideband from 2 to $5.8 \mathrm{GHz}$ with coverage in applications like Bluetooth, LTE, Wi-Fi and WLAN. The reconfigurable nature of the antenna is analyzed with the switching of PIN diodes placed on the antenna structure. The on and off conditions of the diodes D1 and D2 providing switching between the LTE, Wi-Fi and WLAN bands with good impedance matching. The advantage of PIN diodes includes high power handling capability, very low driving voltage and extremely low cost. Here the switch placement and control/biasing strategies depend on the type of the switch and the topology of the antenna. The prototyped antenna with biasing is providing excellent correlation with High Frequency Structure Simulator (HFSS) and Computer Simulation Technology (CST) simulation results. The reconfigurability of the antenna and its parametric optimization is analyzed and presented in this work.
\end{abstract}

Keywords: Asymmetric ground, Coplanar waveguide (CPW), LTE, Reconfigurability, Slot, Wi-Fi, WLAN.

\section{Introduction}

The rapid development in the wireless communication enabling different applications in commercial and military fields [1]. The technology growth switching the multidisciplinary fields to utilize the information in advanced way and giving directions to work in novel environments [2]. The heart of wireless communication lies with efficient and powerful antenna design. The antennas are becoming so compact and smart to serve the needs of modern communication applications [3]. Compact antennas with novel structures to provide high gain, bandwidth and reconfigurable nature is the current research area, which is having lot of scope in the design of advanced communication modules [4].
To allow maximum connectivity in the single wireless platform, more number of radios is to be integrated [5]. Extensive research is under way to develop multiple radio mobile platforms such as Mobile Internet Devices, laptops and smart devices to address different wireless services scattered over a wide frequency range [6]. Researches designing multiple band antennas to addresses different wireless communication applications such as GPS, GSM, PCS, UMTS, Bluetooth, LTE, Wi-Fi and WLAN etc. [7]. These multi band antennas are facing several challenges when more and more wireless services are packed into compact devices [8].

A comparison between antenna solutions and wireless mobile platforms provide different characteristics for the analysis. If the number of 
antennas is used in wireless mobile platform then frequency bands, services and diversity problems should be addressed $[9,10]$. When multi band/wide band antennas are used then wireless modules related diversity problems should be addressed. The individual radio performance is excellent with multiple antennas and good with multi band/wide band antennas. But due to insertion losses at front end the receiver sensitivity will be decreased [11, 12].

The solution for these problems can be obtained by designing reconfigurable antennas. These reconfigurable antennas have multiple advantages like switching to dedicated bands and reduction of interference etc. [13]. The reconfigurable antenna supports only one service at a time with low power consumption at low cost [14]. The reconfigurable antenna usually equipped with switches that are controlled by DC bias signals. By toggling these switches in on and off states, the antenna will be reconfigured to support a dedicated set of operating frequencies [15]. The reconfigurable antennas consist of three types of configurations like frequency reconfigurability, polarisation reconfigurability and hybrid reconfigurability (both frequency and polarisation reconfigurability) [16]. Commonly two major types of switches, PIN diodes and RF MEMS are used in the design of frequency reconfigurable antennas for wireless applications $[17,18]$.

In this article, PIN diodes are used to attain frequency reconfigurability. The advantage of PIN diodes includes high power handling capability, very low driving voltage and extremely low cost [19-20]. Here the switch placement and control/biasing strategies depend on the type of the switch and the topology of the antenna [21, 22]. The DC lines are placed near the radiating elements affected the antenna resonant characteristics [23]. Several antennas are designed with reconfigurable nature in the literature for different communication applications [24, 25], but this proposed antenna model is providing excellent bandwidth for commercial applications with stable gain.

\section{Antenna design}

A. Design specification

The parameters of the antenna are calculated from the formulas given below.

1. Calculation of width $(W)$ :

$$
w=\frac{1}{2 f_{r} \sqrt{\mu_{0} \varepsilon_{0}}} \sqrt{\frac{2}{\varepsilon_{r}+1}}=\frac{c}{2 f_{r}} \sqrt{\frac{2}{\varepsilon_{r}+1}}
$$

Where

$c=$ free space velocity of light

$\varepsilon_{r}=$ Dielectric constant of substrate

2. The effective dielectric constant of the microstrip patch antenna

$$
\varepsilon_{e f f}=\frac{\varepsilon_{r}+1}{2}+\frac{\varepsilon_{r}-1}{2}\left(\frac{1}{\sqrt{1+\frac{12 h}{w}}}\right)
$$

3. The actual length of the patch $(L)$

$$
\begin{aligned}
L & =L_{\text {eff }}-2 \Delta L \\
\text { Where } \quad & L_{\text {eff }}=\frac{c}{2 f_{r} \sqrt{\varepsilon_{e f f}}}
\end{aligned}
$$

\section{Calculation of length extension}

$$
\frac{\Delta L}{h}=0.412 \frac{\left(\varepsilon_{\text {eff }}+0.3\right)\left(\frac{w}{h}+0.264\right)}{\left(\varepsilon_{\text {eff }}-0.258\right)\left(\frac{w}{h}+0.8\right)}
$$

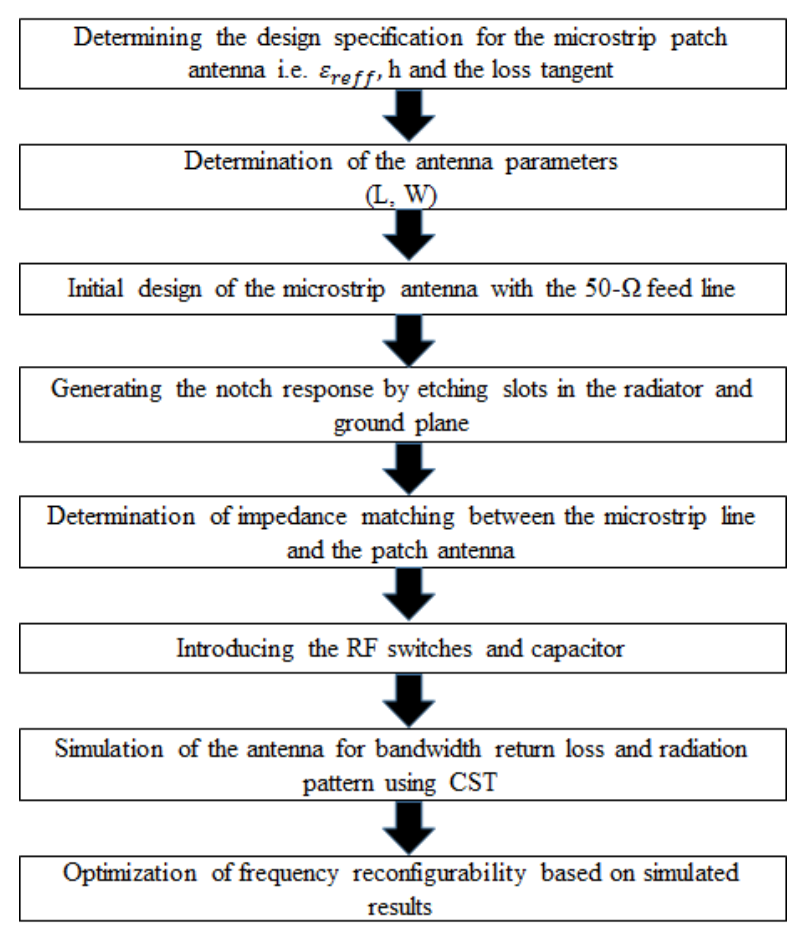


Figure. 1 Design methodology

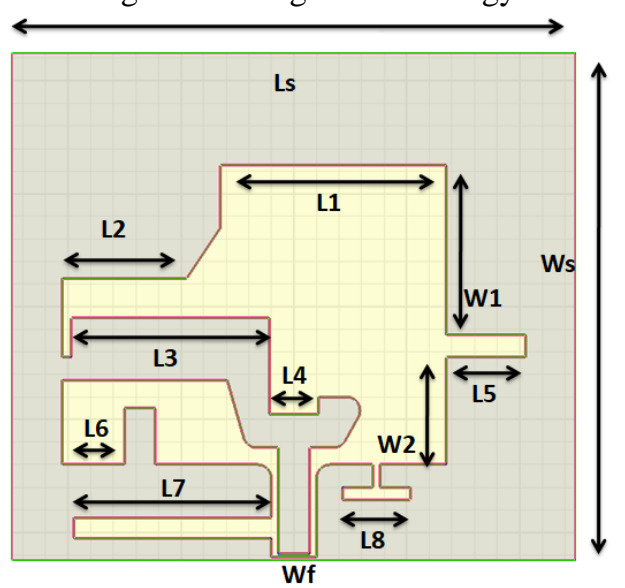

(a)

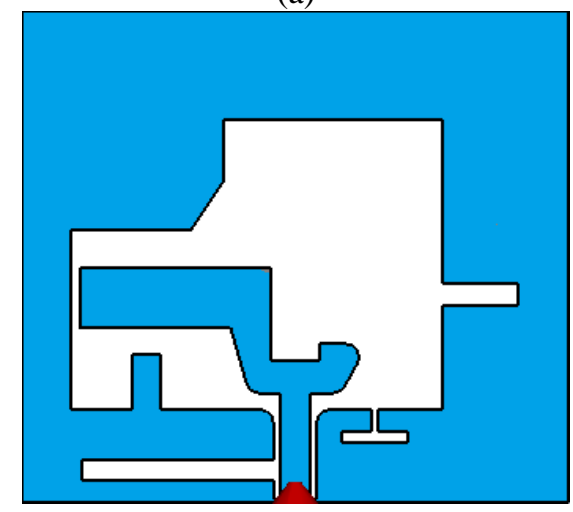

(b)

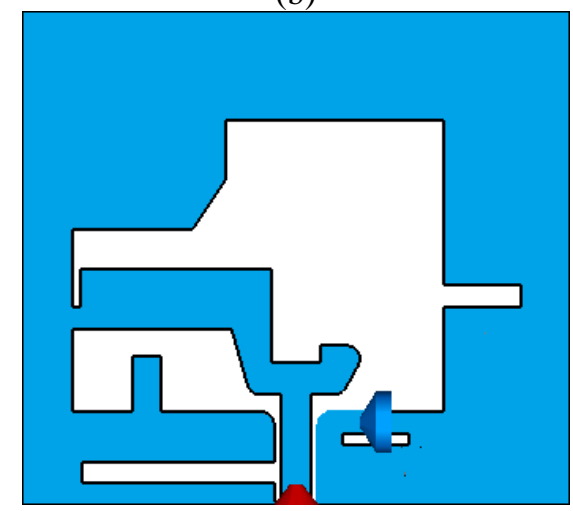

(c)

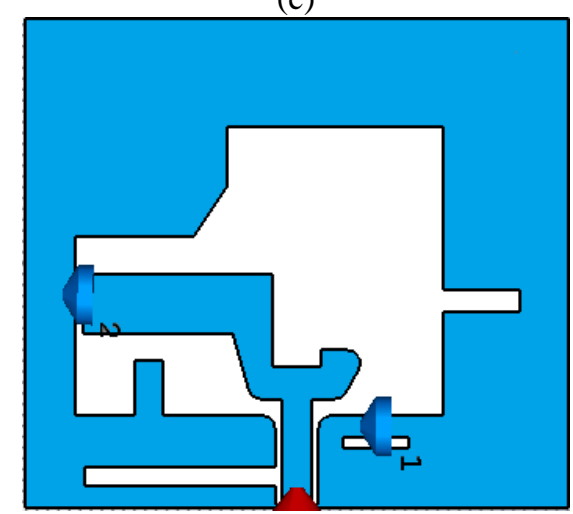

(d)
Table 1. Antenna dimensions

\begin{tabular}{|l|l|l|l|}
\hline Parameter & In $\mathrm{mm}$ & Parameter & In $\mathrm{mm}$ \\
\hline Ls & 45 & L6 & 4.5 \\
\hline Ws & 50 & L7 & 17.5 \\
\hline L1 & 19.5 & L8 & 6 \\
\hline L2 & 11 & Wf & 2.8 \\
\hline L3 & 17.5 & W1 & 10 \\
\hline L4 & 4.4 & W2 & 9.5 \\
\hline L5 & 7 & & \\
\hline
\end{tabular}

The design methodology of the proposed antenna and the steps involved in this process is presented in Fig. 1. The dimensions of the antenna were calculated from the specified equations and the final dimensions are optimized in the simulation process.

The structure of the antenna is very compact in nature and it is occupying the dimension of $50 X 45 \times 1.6 \mathrm{~mm}$ on FR4 substrate with permittivity 4.4. The designed antenna constitutes a monopole on the front side of the substrate with combination of L-shaped stub and U-shaped stub as shown in the Fig. 2 (a). A closed ground with slots are placed on the same side of the substrate to excite it to coplanar waveguide feeding. Two optimized locations are identified to place the diodes and the markings are given on the structure with names D1 and D2 as shown in Fig. 2 (d). To operate the antenna in the band between 2 to $6 \mathrm{GHz}$, the slots on the radiating structure are optimized with respect to impedance matching of 50 ohms. Coplanar waveguide feeding is used for ease of connection and for the improvement of bandwidth. The designed antenna is simulated with HFSS and CST microwave studio and the discussion on the results with analysis is presented in the subsequent sections.

\section{Results and discussion}

Asymmetric ground structured monopole antenna is designed in HFSS and CST tools and the simulated reflection coefficient is presented in Fig. 3. The reflection coefficient obtained from both the tools are matching perfectly and the bandwidth of $3.8 \mathrm{GHz}$ is obtained from HFSS and $3.7 \mathrm{GHz}$ from CST. An impedance bandwidth of $95 \%$ from HFSS tool and $93 \%$ from CST are obtained. The optimized design of the proposed antenna is simulated using the CST Microwave simulation software and the corresponding results of S-parameter, gain, radiation pattern and efficiency are analysed.

Figure. 2 Reconfigurable antenna iterations: (a) antenna 1, (b) antenna 2, (c) antenna 3, and (d) antenna 4 (Proposed) 


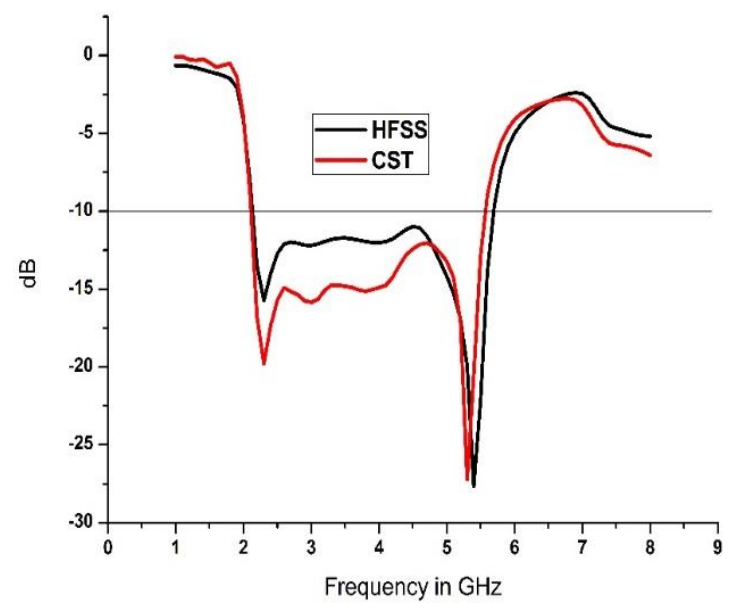

Figure. 3 Reflection coefficient of antenna 1 in CST \& HFSS

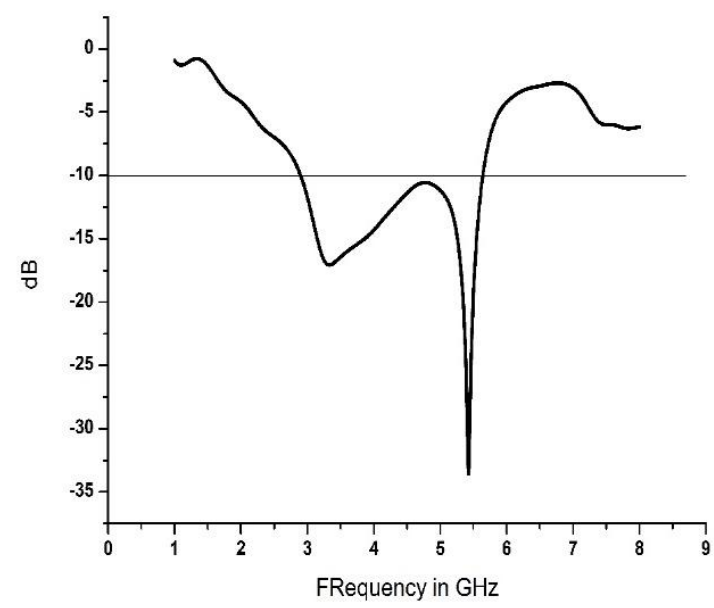

Figure. 4 Reflection coefficient of antenna 2

Antenna model 2 reflection coefficient is simulated and presented in Fig. 4. The antenna model 2 bandwidth is $3 \mathrm{GHz}$ with coverage from 3.8 to $5.8 \mathrm{GHz}$ only. This is due to the slot between Lshaped stub to ground plane as shown in Fig. 2 (b). There is no current flow path between L-shaped stub to ground plane, which causes the degradation in the bandwidth of the antenna.

The reconfigurable nature of the antenna is examined with placement of diodes at two optimized junctions. Initially D1 is placed at ground plane lower right corner, which is adjacent to feedline as shown in Fig. 2 (c). The left side top corner slot is closed in this case to pass the current flow from L-shaped stub. The change in capacitance of the diode is providing reconfigurable behaviour in the operating band. Capacitance of $0.2 \mathrm{pf}$ is the optimized dimension and for the remaining values, the proposed antenna providing notch band characteristics in the wideband.

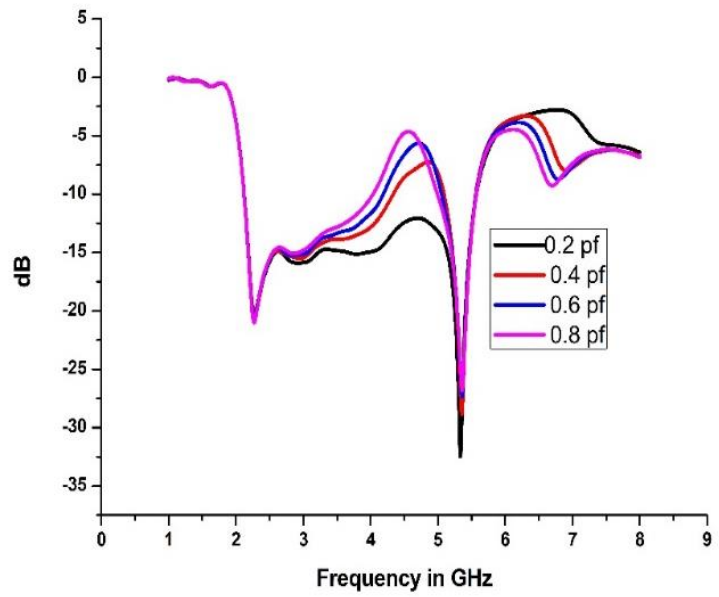

Figure. 5 Frequency reconfigurability of antenna 3
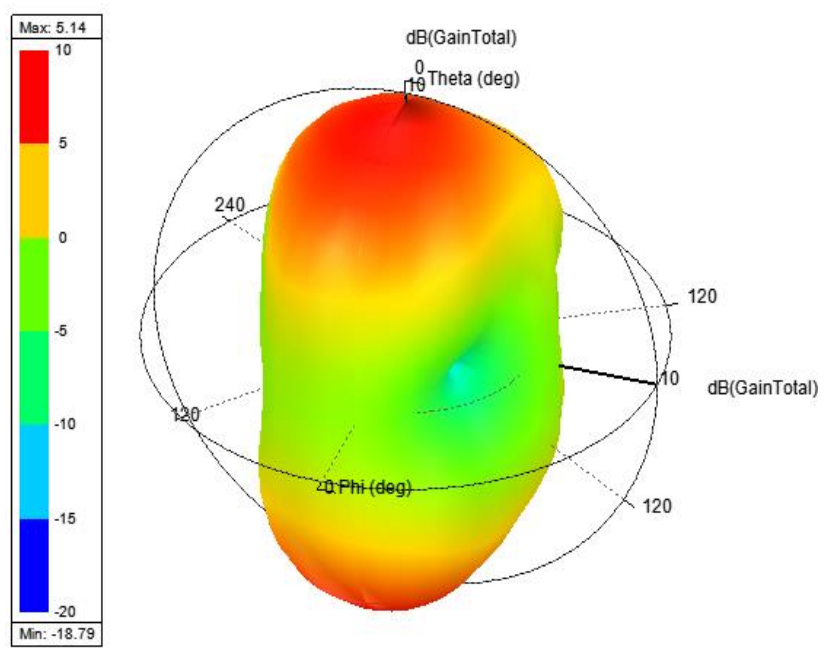

Figure. $63 \mathrm{D}$ Gain at $2.4 \mathrm{GHz}$

The radiation pattern of the proposed antenna at 2.4 GHz and 5.6 GHz are presented in Figs. 6 and 7. At $2.4 \mathrm{GHz}$, antenna showing peak realized gain of $5.14 \mathrm{~dB}$ and at $3.6 \mathrm{GHz}$ it is around $2.81 \mathrm{~dB}$. The impedance characteristics of the antenna is shown in Fig. 8. In the operating band, the impedance is around $50 \mathrm{ohms}$ and which is the most considerable parameter in the impedance matching. The radiation pattern in polar coordinates for $2.4 \mathrm{GHz}$ is shown in Figs. 9 and 10. Antenna showing omni directional pattern radiation in $\mathrm{H}$-plane with low cross polarization and dipole like pattern in the E-plane. It is also noted that the H-plane pattern show relatively low cross polarization radiation. This behaviour is largely due to the strong horizontal components of the surface current and electric field observed, when leads to a significant increase of the co-polarization radiation. 

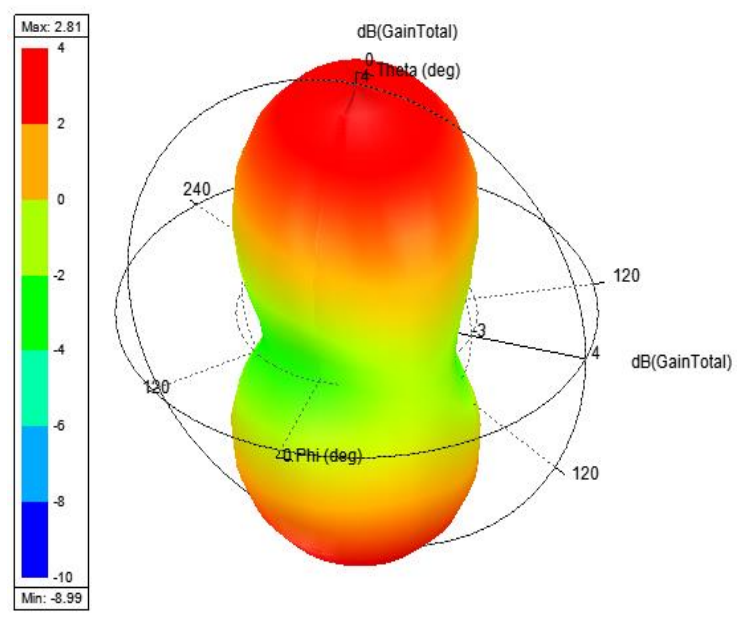

Figure. 7 3D Gain at $5.6 \mathrm{GHz}$

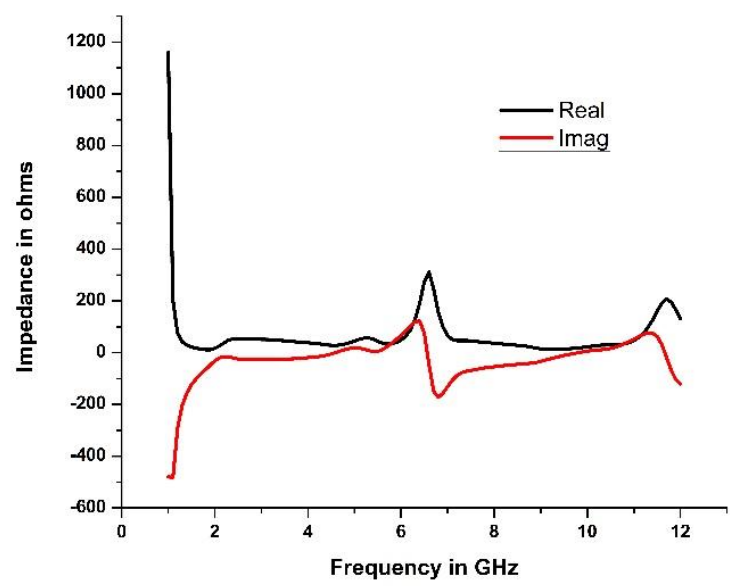

Figure. 8 Frequency vs. impedance

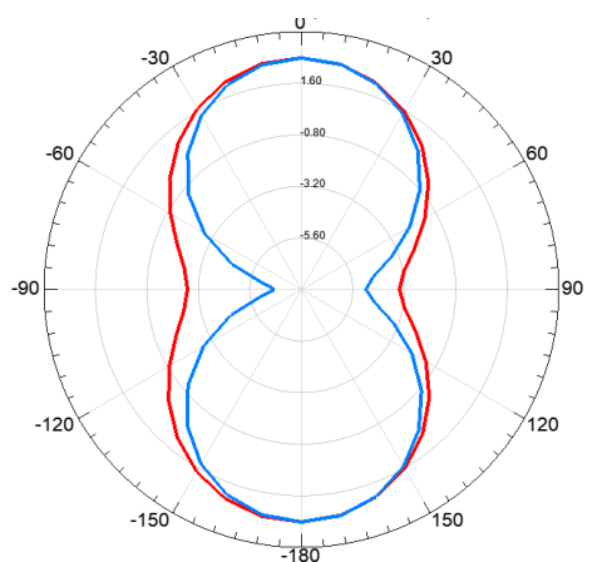

Figure. 9 E-Plane radiation at $2.4 \mathrm{GHz}$

The surface current distribution of the antenna at 2.4 GHz is shown in the Fig. 11. The current intensity is focussed at lower half of the antenna and mostly at feed line and at the adjacent right corner. The vertical component of the surface current which contributes for major radiation and the horizontal component contributes the cross polarization.

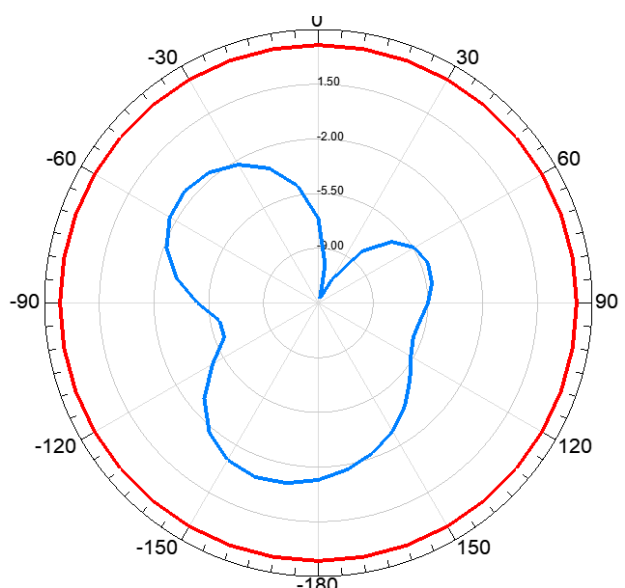

Figure. $10 \mathrm{H}$-Plane radiation at $2.4 \mathrm{GHz}$

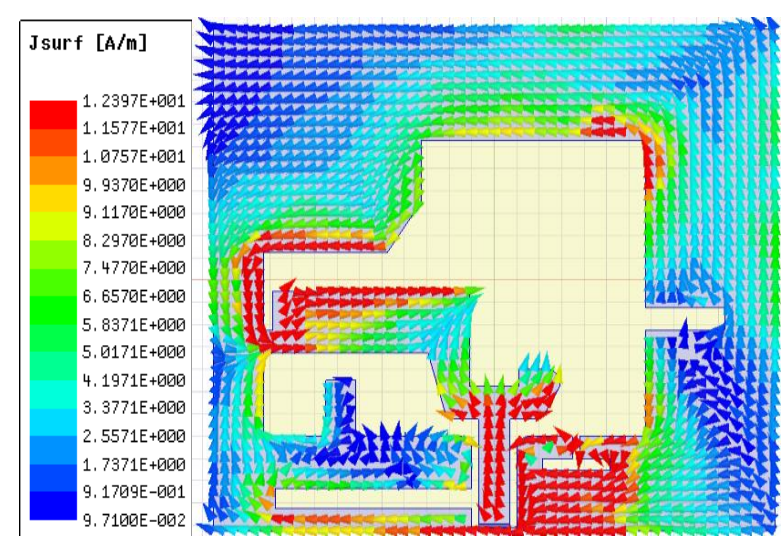

Figure. 11 Surface current distribution at $2.4 \mathrm{GHz}$

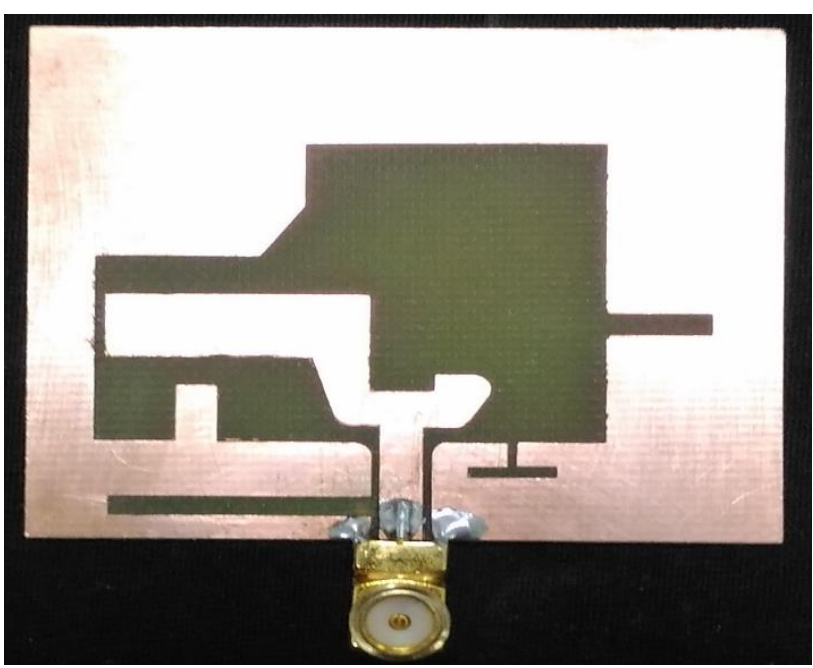

Figure. 12 Prototyped wideband antenna

The slots are made in the maximum current flowing paths and diodes are connected for frequency tuning. The diodes swithing in the approporiate locations provided the band stopping and band passing characteristics, which inturn controlled the frequency tuning operation. 


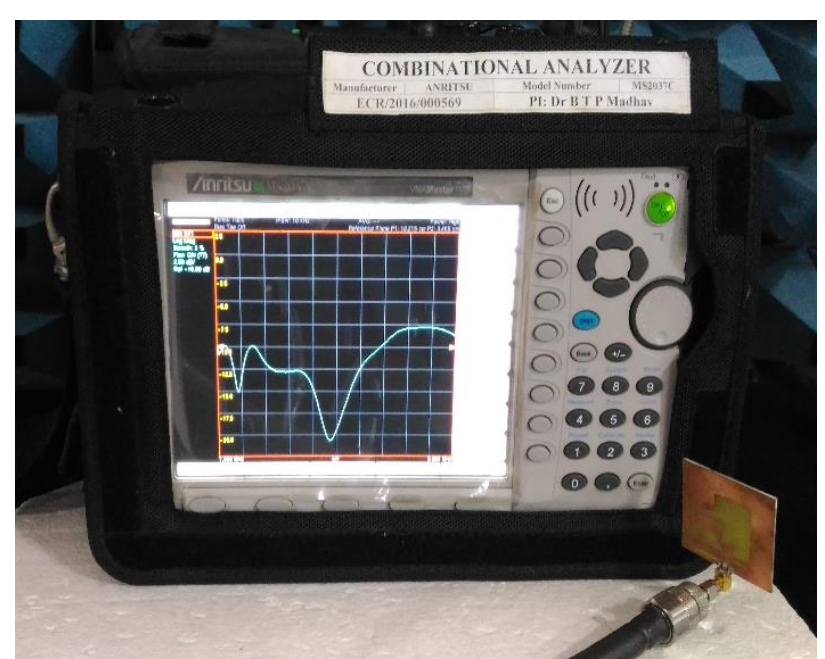

Figure. $13 \mathrm{~S}_{11}$ measurement of prototyped wideband antenna

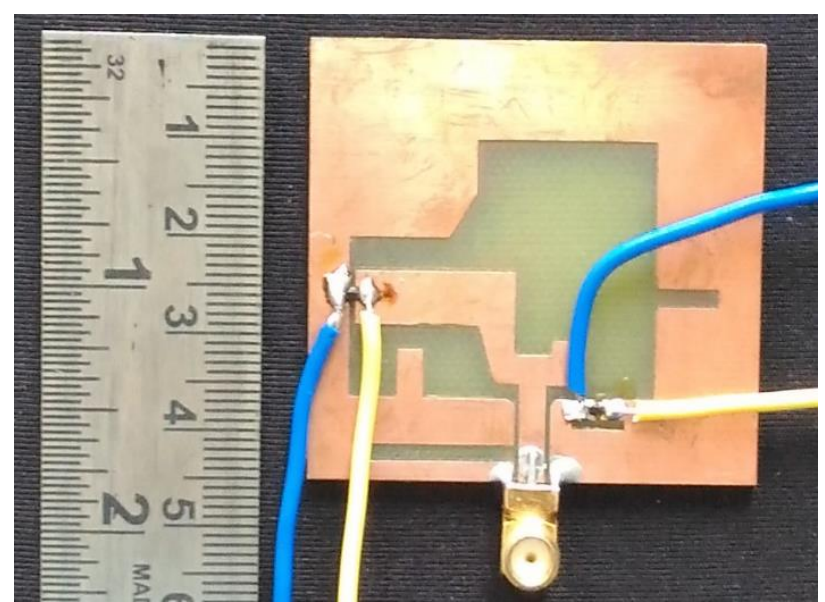

Figure. 14 Proposed reconfigurable antenna with PIN diodes and biasing lines

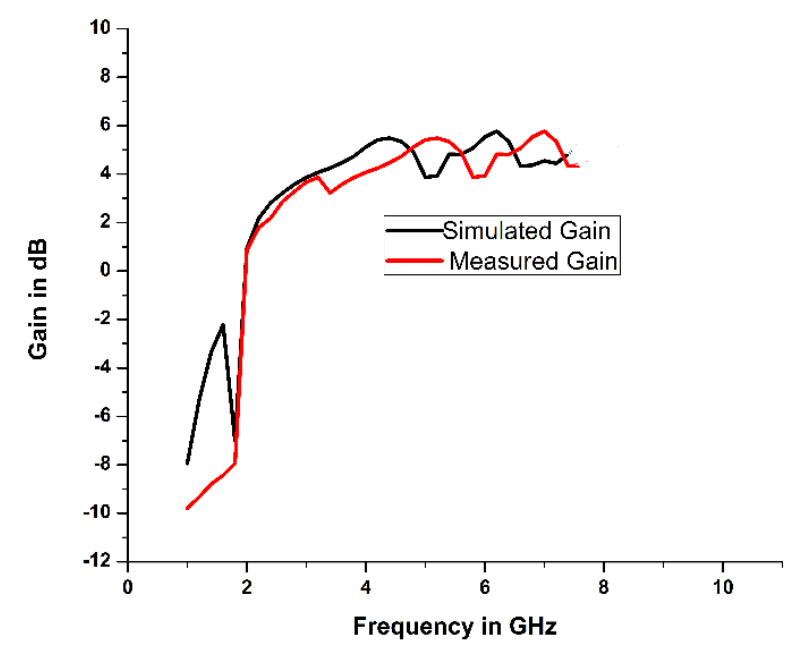

Figure. 15 Frequency vs. gain

The wideband antenna is prototyped on FR4 substrate and the modified proposed reconfigurable antenna are presented in Figs. 12 and 14. Sma connector $50 \mathrm{ohms}$ is connected at the feed point to measure the antenna parameters through aniritsu combination analyzer at antennas and liquid crystals research centre of KLEF. The measured gain and the simulated gain of the antenna is presented in Fig. 15 and the measured VSWR with simulated results are presented in Fig. 16.

A good correlation between simulation and measurement can be observed from the presented results. The gain is little bit high at higher operating band and an average gain of $4.5 \mathrm{~dB}$ is attained in the operating band.

The prototyped antenna is tested for its reconfigurable nature by applying bias voltage to the diodes and the corresponding change in reflection coefficient is presented in Fig. 17. Small shift in the notch band towards higher frequency band can be observed from the experimented results.

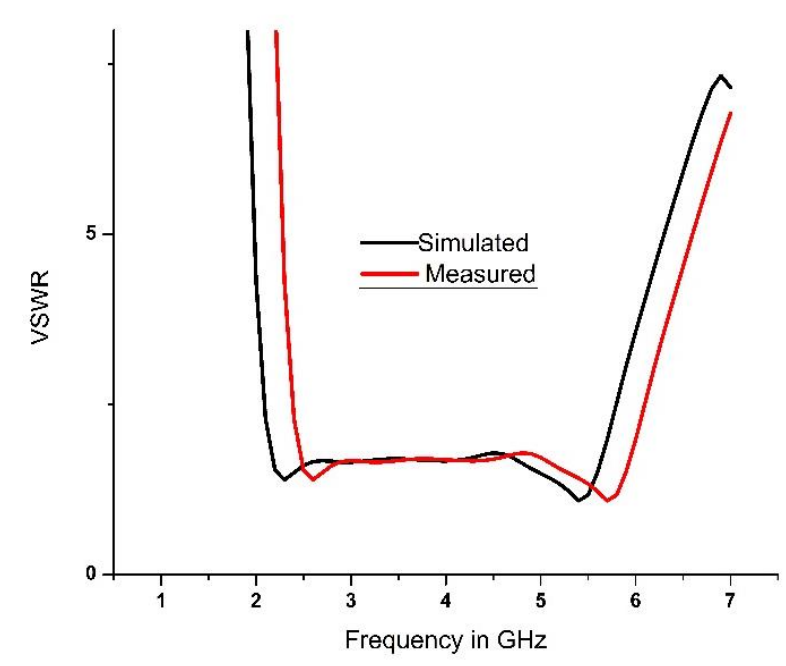

Figure. 16 Simulated and measured VSWR

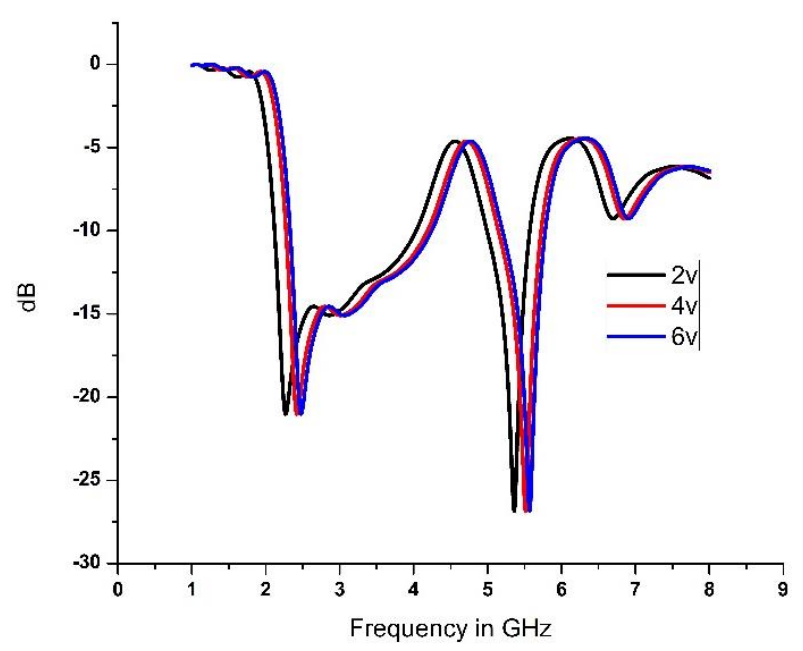

Figure. 17 Reconfigurability measurement by applying bias voltage 
Table 2. Proposed model comparison with literature

\begin{tabular}{|l|l|l|l|}
\hline Ref. No & $\begin{array}{l}\text { Size in } \\
\text { mm }\end{array}$ & $\begin{array}{l}\text { Bandwidth } \\
\text { in GHz }\end{array}$ & $\begin{array}{l}\text { Gain in } \\
\text { dB }\end{array}$ \\
\hline 1 & 56 X48X1.6 & 3.2 & 4.68 \\
\hline 2 & $58 X 52 X 1.6$ & 3.6 & 4.26 \\
\hline 6 & $64 X 58 X 1.6$ & 3 & 4,56 \\
\hline 18 & $54 X 50 \times 0.8$ & 3.6 & 4.8 \\
\hline 19 & $60 X 56 X 1.6$ & 2.2 & 5.1 \\
\hline Proposed & $50 X 45 X 1.6$ & 3.8 & 5.14 \\
\hline
\end{tabular}

A comparative analysis of proposed antenna with other models available in the literature is presented in Table 2. As per the size and bandwidth is concerned, the proposed antenna is providing superior results over other models. Gain is also little bit high over other antennas.

\section{Conclusion}

A stable gain frequency reconfigurable antenna with asymmetric ground plane is presented in this paper. The frequency reconfigurability is attained through PIN diodes switching operation and the obtained simulation results are giving good matching with measured results of the prototyped antenna model. The on and off conditions of the diodes D1 and D2 providing switching between the LTE, Wi-Fi and WLAN bands with good impedance matching. Peak realized gain of $5.14 \mathrm{~dB}$, average gain of $4.5 \mathrm{~dB}$ and efficiency more than $75 \%$ are the attractive features of the proposed antenna model. The gain and the efficiency can be further improved with the placement of frequency selective surface beneath the ground plane as future work and further the back lobes can be reduced effectively.

\section{Acknowledgments}

We acknowledge ECE of KLEF and DST ECR/ 2016/ 000569, SR/FST/ETI-316/2012 and EEQ/ 2016/ 000604.

\section{References}

[1] T. Li, H. Zhai, X. Wang, L. Li, and C. Liang, "Frequency-Reconfigurable Bow-Tie Antenna for Bluetooth, WiMAX, and WLAN Applications", IEEE Antennas and Wireless Propagation Letters, Vol. 14, pp. 171-174, 2015.

[2] S. Al-Zayed, M. A. Kourah, and S. F. Mahmoud, "Frequency-reconfigurable single- and dualband designs of a multi-mode microstrip antenna", IET Microwaves, Antennas \& Propagation, Vol. 8, No. 13, pp. 1105-1112, 2014.
[3] D. S. Rao and J. L. Narayana, "Microstrip Parasitic Strip Loaded Reconfigurable Monopole Antenna", ARPN Journal of Engineering and Applied Sciences, Vol. 11, No. 19, pp. 1-7, 2016.

[4] K. Supraja, "K15 Nematic Phase Liquid Crystal Material Based Double-Dipole Reconfigurable Antenna", Rasayan Journal of Chemistry, Vol. 10, No. 3, pp 866-872, 2017.

[5] M. A. Babu, B. M. Reddy, R. D. Chaitanya, T. Satish, and T. Anilkumar, "A Dual-Polarization Reconfigurable Antenna with Beam Switching Characteristics For S-Band Applications", ARPN Journal of Engineering and Applied Sciences, Vol. 12, No. 16, pp 4841-4847, 2017.

[6] K. Murthy, K. Umakantham, K. S. Murthy, and B. T. P. Madhav, "Reconfigurable Notch Band Monopole Slot Antenna for WLAN/IEEE802.11n Applications", International Journal of Intelligent Engineering and Systems, Vol. 10, No. 6, pp 166-173, 2017.

[7] T. V. Ramakrishna, N. Kiran, B. Sravani, N. Vamsi, and K. L. Yamini, "Frequency Reconfigurable Antenna for Ku-Band Applications", ARPN Journal of Engineering and Applied Sciences, Vol. 12, No. 22, pp 65276532, 2017.

[8] G. J. Devi, "Reconfigurable MIMO Antenna For 5G Communication Applications", International Journal of Pure and Applied Mathematics, Vol. 117, No. 18, pp 89-95, 2017.

[9] U. Ramya, M. A. Babu, and M. V. Rao, "Double Notch Reconfigurable Monopole Antenna with Stub Loaded DGS", International Journal of Pure and Applied Mathematics, Vol. 117, No. 18, pp 97-103, 2017.

[10] P. F. Banu, G. H. S. Teja, P. Prashanth, and K. L. Yamini, "Octagonal Shaped Frequency Reconfigurable Antenna for Wi-Fi and WiMAX Applications", Lecture Notes in Electrical Engineering, Vol. 471, pp 581-588, 2018.

[11] G. Lalitha, S. M. Parvez, J. Naveen, D. Mani Deepak, and A. N. M. Kumari, "A Frequency Reconfigurable Spiral F-Shaped Antenna for Multiple Mobile Applications", Lecture Notes in Electrical Engineering, Vol. 471, pp 571-580, 2018.

[12] K. S. R. Murthy, K. Umakantham, and K. S. N. Murthy, "U-Shaped Slotted Reconfigurable Monopole with WIMAX Band Notching", Journal of Advanced Research in Dynamical and Control Systems, Vol. 9, No. 14, pp 19111919, 2017. 
[13] B. S. Prasad and P. M. Rao, "CPW Fed T-Stub And U-Slot Reconfigurable Antenna for Wi-Fi And WLAN Communication Applications", Journal of Advanced Research in Dynamical and Control Systems, Vol. 9, No. 14, pp 21042116, 2017.

[14] A. Vamseekrishna, Y. Nagarjuna, S. L. Manasa, V. Mourya, and Y. Yaswant, "Reconfigurable Notch Band Antenna Using PIN Diodes", Journal of Advanced Research in Dynamical and Control Systems, Vol. 9, Issue 14, pp 17461754, 2017.

[15] B. S. Prasad and P. M. Rao, "Coplanar Wave guide fed fork shaped frequency reconfigurable antenna for LTE, Wi-Fi and WLAN applications", International Journal of Engineering and Technology, Vol. 7, No. 1.1, pp 366-370, 2018.

[16] Y. B. Dhanade, K. Sreelakshmi, P. Bora, and M. Mudliar, "Frequency Reconfigurable Dual Band Antenna for Wireless Communications", Journal of Advanced Research in Dynamical and Control Systems, Vol. 9, No. 14, pp 23282345, 2017.

[17] M. V. Rao, "Design and Analysis of Stepped Reconfigurable Rectangular Patch Antenna for LTE, Vehicular and Ultra Wideband Applications", International Journal of Engineering and Technology, Vol. 7, No. 1.1, pp 548-553, 2018.

[18] P. Pardhasaradhi and T. Anilkumar, "Design of Compact Reconfigurable Antenna with Triple Band Switchable Characteristics", International Journal of Engineering and Technology, Vol. 7, No. 1.1, pp 554-559, 2018.

[19] A. Vamseekrishna, "A Frequency Reconfigurable Antenna with Bluetooth, Wi-Fi and WLAN Notch Band Characteristics", International Journal of Engineering and Technology, Vol. 7, No. 2.7, pp 127-130, 2018.

[20] X. L. Yang, J. C. Lin, G. Chen, and F. L. Kong, "Frequency Reconfigurable Antenna for Wireless Communications Using GaAs FET Switch", IEEE Antennas and Wireless Propagation Letters, Vol. 14, pp. 807-810, 2015.

[21] L. Ge and K. M. Luk, "FrequencyReconfigurable Low-Profile Circular Monopolar Patch Antenna", IEEE Transactions on Antennas and Propagation, Vol. 62, No. 7, pp. 3443-3449, 2014.

[22] S. Al-Zayed, M. A. Kourah, and S. F. Mahmoud, "Frequency-reconfigurable singleand dual-band designs of a multi-mode microstrip antenna", IET Microwaves, Antennas
\& Propagation, Vol. 8, No. 13, pp. 1105-1112, 2014.

[23] Q. Liu, N. Wang, C. Wu, G. Wei, and A. B. Smolders, "Frequency Reconfigurable Antenna Controlled by Multi-Reed Switches", IEEE Antennas and Wireless Propagation Letters, Vol. 14, pp. 927-930, 2015.

[24] D. S. R. Kiran and V. Alekhya, "An Asymmetric Liquid Crystal Polymer Based Fractal Slotted UWB Monopole Antenna with Notch Band Characteristics", Rasayan Journal of Chemistry, Vol. 10, No. 3, pp 852-860, 2017.

[25] B. T. P. Madhav, T. V. Rao, and T. A. Kumar, "Design of 4-Element Printed Array Antenna for Ultra-Wideband Applications", International Journal of Microwave and Optical Technology, Vol. 13, No. 1, pp 8-17, 2018. 